\title{
COMPUTER LITERACY AND THE DEVELOPING WORLD: THE BRIDGE TO INFORMATION
}

\author{
Winston Tellis, Dolan School of Business, Fairfield University
}

\begin{abstract}
The widespread use of the Internet for knowledge acquisition is commonplace in the developed world. However, in developing countries, where resources are limited, the infrastructure to support networking could be scarce. This pilot project is a design for implementing a program to train teachers to use laptops in their classroom instruction, and for students to have access to the laptops for assignments. Senegal is a peaceful country, but resources to introduce computers in elementary education are not available. This project will address teacher training, and wireless Internet access in one school, and will ensure the sustainability of the project by engaging trained teachers to train future teachers.
\end{abstract}

Keywords: Education, Digital divide, Wireless, Senegal, Teacher training.

\section{INTRODUCTION}

A student from Senegal asked the author to help him introduce PCs into his grade school in Dakar, Senegal. When he arrived in the US, his first assignment was to write an essay using Microsoft Word. He had never used a computer, much less be prepared to submit his work in Word. Using prior experience, the author established methodologies from the literature, and designed a plan to implement the use of personal computers in one grade school in Dakar, Senegal. It is a pilot project and it could be extended to five neighboring schools, with appropriate adjustments. The growing reliance on the Internet for knowledge acquisition makes it imperative that the "digital divide" is reduced wherever possible. This project would enable the students in one school to learn how to access information over the Internet, and enable the teachers to access resources to enhance their own professionalism.

Teacher training is of critical importance in ensuring the sustainability of this project, and its subsequent expansion to additional schools. The author contacted the Principal at the selected school, who with the
Advisory Board provided a set of goals and objectives. However, those goals were narrowly defined; they did not address the integration of computers into the curriculum. Pretest and Posttest data will guide the design of the project in the other schools. Wireless Internet access will be installed with local expertise, but the author would need to inspect the site, and to assess the prevailing conditions and adjust the research design.

\section{Country}

Senegal is one of the most stable democracies in Africa. Senegal was ruled by a Socialist Party for 40 years until current President Abdoulaye Wade was elected in 2000, and reelected in February 2007. Senegal has a population of approximately $12,853,259$ people, $42 \%$ of who are between the ages of 0 and 14 years of age, and $55 \%$ between 15 and 64 years, roughly evenly divided between males and females [4].

The official language is French, Senegal, having been colonized by France, secondary and tertiary languages in Senegal include Wolof, Pulaar, Jola, and Mandinka. The climate is hot and humid [4]. Most people follow the Muslim religion (94\%) and about $5 \%$ are Christian [4]. The literacy rate is about $39 \%$ overall, although for males it is $51 \%$, but only $29 \%$ for females - a pattern that is common in many Muslim countries, and higher in cities than in rural areas [4].

Medina is a large community within the capital, Dakar. It is an upper-middle class and a multicultural environment. One school named Sacoura Badiane, is surrounded by many other schools, within a short distance of one another, and the target school for this pilot project.

\section{Education system}

There are 3,884 primary schools in the country [20], with 30 libraries in the entire country. The educational enrollment declines sharply from primary to secondary and higher-level schools. In the primary level, the attendance rate is $71 \%$, for the secondary 
level, it is $16 \%$, and for the highest level, it is only $3 \%$ [20]. There are 18,373 teachers in primary schools. The teacher-to-student ratio in the primary schools is roughly $56: 1$ and $24: 1$ in the secondary [20]. 52 percent of the men and 72 percent of the women, 15 years of age and over, are illiterate [18]. Only $39 \%$ of the total population can read and write, of which $51 \%$ of the males and $29 \%$ of the females are literate [4].

The reason for introducing computers into the schools in Dakar is to start the children using them at a very young age. There is little opportunity to access technology, since many students have no resources, and cannot afford to buy a computer. If the children in Dakar are introduced to computers, they will be part of the digital age.

\section{PC options for developing countries}

Organizations interested in using technology, have limited options for acquiring personal computers for use in schools. Most of the organizations internationally known for their innovative and cost effective alternatives to the commercial units, only work at the national level with governments or departments of education. The most visible effort to make laptops available to developing countries is the "One Laptop Per Child" program developed by Nicholas Negroponte, and the other is Intel Corporation's "Classmate" program. Neither option is available to local school systems. The author communicated with both organizations for this article, and received a response only from Intel, explaining their inability to accept orders from a group other than the national government.

\section{One Laptop Per Child (OLPC)}

Two-billion children in the developing world are inadequately educated or they simply do not receive education at all [14]. This is causing a major crisis for the individuals and society in these countries, where poverty limits the people's horizons.

\section{Product}

The XO-1, previously known as the $\$ 100$ Laptop, is an inexpensive laptop computer designed for distribution to children in developing countries. The main purpose is to provide equal access to knowledge that is currently lacking in those countries.

\section{Intel Classmate}

Volume X, No. 2, 2009
The World Ahead Program from Intel Corporation aims to enhance lives by accelerating access to uncompromised technology for everyone, anywhere in the world, but particularly in the emerging markets. Intel's efforts are aimed to advance progress in four areas: accessibility, connectivity, education, and content. Intel has ongoing programs prepare teachers and students for success in the global economy.

\section{Product}

The Classmate is designed for education with a durable rugged design for children's day-to-day use. It has education-specific features such as, integrated software and hardware solutions, learning through fun, collaboration, and interaction, and it is easy to deploy. It runs several Operating Systems, and is compatible with the major products today.

The above two options OLPC and Classmate, are designed to respond to national organizations, where negotiations take place between the vendor and the local government or ministerial level department. Principals in small schools face several serious problems. The cost of the units described above is beyond the capacity of these small schools to absorb into their budgets. On the other hand, the large vendors are not in a position to entertain requests from small schools, perhaps for logistical reasons. Another consideration is developing a plan to integrate the PCs into the school curriculum in an orderly manner. This involves teacher training, language specific curriculum development, adjusted "lesson plans," and even time allocated to computer use. Few schools have the resources and the expertise to embark on this endeavor.

This pilot project is designed to address the dilemma facing such school Principals. The author identified a small school in Dakar, which one of the author's students attended, and received encouragement from the Principal, Mr. Abdoulaye N'Diaye to develop an implementation plan. In addition to developing the teacher-training program, the infrastructure to support Wireless Internet access will be evaluated during a scheduled site visit in December 2009. A general "Wifi" plan based on an installation in Venezuela developed by Avidity Inc. appears in Appendix A.

\section{Implementation Plan}

Issues in Information Systems 
There are several viable methodologies for the introduction of PCs into an educational environment. The author reviewed a document outlining a five-step procedure to deploying eLearning environments (eLearning for the $21^{\text {st }}$ Century, 2008). As with the other implementation plans, this plan was not precisely suitable for the environment in Dakar. However, it is a suitable starting point for a new installation. The five steps in this plan are:

1) Assess objectives and constraints

2) Specify a solution based on assessment

3) Pilot the solution to be deployed

4) Finalize the solution based on the results of the pilot

5) Deploy the solution on a broad scale.

Within each broad step there are supporting activities, which require careful review and assessment for the environment in which they will be implemented. Using the five-step procedure for deploying eLearning environments [8] as described earlier, the author developed an implementation plan for the Sacoura Badiane elementary school, as well as the accompanying activity items within each step, as follows:

1. Assess objectives and constraints

\section{Activity 1: Define the vision.}

Form an Advisory Board with all constituencies.

The Principal, Mr. N'Diaye convened a representative group of 18 individuals [13]. Based on their assessment, they developed a vision for this project, its objectives, and the obstacles they might encounter: "The children of the school will become proficient in the use of the new technology of information and communication, the pupil who leaves the school at the end of 5 years will be able to manipulate the computer and regulate his own social problems. The teachers will develop teaching materials with modern tools, and will enhance their innovative teaching methods."

\section{Activity 2: Define Educational Objectives.}

The Board defined the learning objectives: the students should learn,

a) How to format text

b) How to do his or her own assignment using the computer

c) How to calculate his or her average grades using Excel

d) How to send an email

e) How to write and send a letter

Volume X, No. 2, 2009
While the Principal was open to the idea of teacher training, the goals that his Board developed were limited by the scope of their personal experience. Those skills are an essential element in the development of any computer user in the digital age. However, this project seeks to engage the teachers in the integration of computers in the courses such as Mathematics, Science, History, and others. In addition, the training would assist the teachers in developing assignments so that the students would have the opportunity to practice the material imparted in class.

\section{Activity 3: Assess Existing Technology and Education Environment}

There are no computers or telephones in the school. Students and teachers must leave the school to use the telephone or Internet at nearby Internet Cafes. The class size is usually over 30 students. With a scarcity of textbooks, students take copious notes. Most teachers have the Certificate Aptitude Professional (CAP). The project would have to identify a local ISP capable of installing a wireless network in the school, with a wired connection to the ISP's external Internet connection. The author plans a site visit to assess the progress of the school community and its partners in preparing for the pilot project.

\section{Activity 4: Assess Energy and Geographic Constraints}

The school has electricity and running water. Network cabling could be a technical and maintenance challenge. Hence, wireless network service would be necessary, and would be installed by a local ISP indentified by the school Principal.

\section{Activity 5: Assess Training Needs and Available Methods}

The Principal's Advisory Board is committed to ensuring that these computers are used well and therefore, it is critical that the school's teachers are trained to use them prior to student use. A pretest would be administered to the teachers to determine their level of computer literacy. In addition, the literature would be helpful in devising a training program that would assist the teachers with integrating computer use in their subject specialty.

\section{Activity 6: Assess Costs, Benefits, and Feasibility}

This pilot implementation was designed to minimize expenses so that the project might proceed. The cost
Issues in Information Systems 
items that the Advisory group should examine are the Internet Service Provider, Teacher Training, and the Wireless Network within the school. The researcher will continue to evaluate the cost of individual items, and then to develop a budget.

The teachers should emerge from the training with mastery of the technology. They should also prepare specific lesson plans in their respective subject areas, so that they would be functional at Sacoura Badiane as soon as they return. This would benefit the school and the students as the teachers confidently lead their classes in this new direction, and they would be confident in their leadership. The mastery of the technology is a preliminary step to the integration of the computer use in the instruction. Thus, the teacher training should also include detailed planning for the candidate teachers, who will emerge from the training with the confidence not only to conduct their own classes, but when the project expands to neighboring schools, they would be the trainers for their peers. There is a rich body of literature on this topic, but the author would have to work with the Principal to modify the training materials to be culturally sensitive.

\section{Activity 7: Define Success Metrics and Evaluation Process}

The researcher will administer a survey to gather data on pre-implementation student skills in the areas of the Advisory Board's objectives. Those skills would be measured with existing instruments modified for the prevailing environment [3]. The researcher will administer the instrument one year after implementation of the project to determine whether there is measureable change [3]

2. Specify a solution based on assessment.

The researcher will examine the pre-test results to design the Teacher training to meet the Board's objectives, and the student lesson plans would be developed for the teachers to integrate the use of computers in their areas of expertise.

3. Pilot the solution to be deployed.

The first phase in the plan is for the teachers to be trained, and to be ready with lesson plans and homework assignments. The teachers will maintain records of the assignments and the students' progress through the lessons and the amount of time taken for each assignment. The records will be useful in assessing the success of the instruction, and will help determine whether additional computers would be needed.

4. Finalize the solution based on the results of the pilot.

Volume X, No. 2, 2009
The results of the pilot project will inform the process for the expansion of the project to the five other schools in the neighborhood.

5. Deploy the solution on a broad scale.

With each school's plan developed by the respective Boards, the expansion would have a more reasonable chance of success. The technical impediments would have been addressed in the Sacoura Badiane pilot project. The Wireless network installed at Sacoura Badiane, could serve all the other schools through the WiFi system described in Appendix A.

\section{CONCLUSION}

This report was designed to investigate the feasibility of introducing computers into one school in Dakar, capital of Senegal. Conversations with the local school Principal and with a US based network consultant with experience in developing countries, led to a pilot project design that includes teacher training in the use of technology, as well as in the integration of computer use in the classroom instruction. Modified pretest and posttest instruments will be administered to the teachers and students to assess the effectiveness of the training. The results of those tests will inform the subsequent expansion of the project to the five neighboring schools. The initial visit is scheduled for December 2009, and pilot implementation in June 2010.

\section{REFERENCES}

1. Abdoulaye, N'Diaye, Telephone interview. 6 Apr. 2008.

2. Bates, A., (2004), Managing Technological Change: Strategies For College And University Leaders San Francisco: Jossey Bass/John Wiley.

3. Bradlow, E.,Hoch, S., Hutchinson, J., (2002), An Assessment of Basic Computer Proficiency Among Active Internet Users: Test Construction, Calibration, Antecedents and Consequences, Journal of Educational Behavioral Statistics, 27, 3, p237, fall 2002.

4. CIA FACT https://www.cia.gov/library/publications/theworld-factbook/geos/sg.html

5. Classmate Information, 2008, http://www.classmatepc.com.

6. Dakar Facts, 2008, http://en.wikipedia.org/wiki/Dakar

7. Divjak, B., Begičević, N., (2006) Imaginative acquisition of knowledge-strategic planning of elearning, Proceedings on $28^{\text {th }}$ International Conference on Information Technology Interfaces. 
8. eLearning for the $21^{\text {st }}$ Century, 2008, http://www.intel.com/worldahead

9. Intel Classmate, 2008, http://www.intel.com/intel/worldahead/classmate pc.

10. Intel Education, 2008, http://www.intel.com/intel/worldahead/education .htm?iid=worldahead+ln_education

11. Kim, C., Santiago R., (2005), Construction of Elearning environments in Korea, Educational Technology, Research and Development, v53(4), p108.

12. Michel, Claudine. "Senegal" in World Education Encyclopedia, ed. George Thomas Kurian. New York: Facts on File, 1988.

13. N'Diaye, A., (2008), Report from Advisory Board, December, 2008.

14. Negroponte, N., "One Laptop Per Child", 9 Apr. 2008, http://laptop.org/vision/mission.

15. OLPC Design, 2008, http://laptop.org/en/laptop/design.

16. OLPC Software, 2008, http://laptop.org/en/laptop/software.

17. Senegal - History, http://education.stateuniversity.com/pages/1319/ Senegal.html Senegal - History \& Background, Constitutional \& Legal Foundations, Educational System-overview, Preprimary \& Primary Education, Secondary Education.

18. Senegal - Educational System, Education Encyclopedia - StateUniversity.Com, 24 Mar. 2008,

http://education.stateuniversity.com/pages/1311/

Senegal-EDUCATIONAL-SYSTEM-

OVERVIEW.html.

19. Sy, Dianga, "Microsoft Launches Dakar Office, Seals Partnership with Government" Microsoft Corporation, 26 Apr. 2008, <http://www.microsoft.com>.

20. Yoder, L., "Global Education Reference Senegal", Education Encyclopedia - "The World Factbook", CIA, 22 Apr. 2008, https://www.cia.gov/library/publications/theworld-factbook/geos/sg.html

StateUniversity.Com, 23 Mar. 2008.

\section{APPENDIX A}

\section{Wireless setup/ Wifi signal}

The design took into consideration maximum reliability and coverage at speeds ranging from 1 to $54 \mathrm{Mbps}$. The proposed network is based on Wireless Fidelity (WiFi), $802.11 \mathrm{a} / \mathrm{b} / \mathrm{g}$, which supports speeds up to $54 \mathrm{Mbps}$ with equipment manufactured by

Volume X, No. 2, 2009
Colubris Networks (www.colubris.com) one of the world leaders in the implementation of Wifi networks for educational institutions.

The service provider is assumed to be located at a distance of no more than 5 miles, without any obstacles (i.e. clear line of sight). Internet signal will be sent via unidirectional antennas in a point-to-point configuration. At the school, the signal will be captured via an Access controller and fed into a LAN switch. To reduce power requirements, the proposed LAN switch will be Power Over Ethernet (PoE) capable. The signal is then propagated into three Access Points for total coverage of speeds ranging from 1 to 54 Mbps.

Bringing Internet to Dakar

a) Internet connection

\section{i) Limitations of performance}

The proposed network is capable of supporting an unlimited number of AP and controllers. Each Access Controller can support up to 500 simultaneous users. Therefore, as is, the system can support a maximum of 500 concurrent clients; for greater capacity additional Access Controller must be considered or replaced with Access Controllers capable of supporting of up to 2000 simultaneous users.

\section{ii) Security}

Though sufficient care has been taken to minimize the signal spillage outside the deployment area, it cannot be completely avoided. Due to the nonphysical medium of transport, WLAN deployments are inherently much more vulnerable to security breaches than the traditional wired LANs. Additionally, WLANs can also be difficult to maintain. Diagnosing and troubleshooting WLANs is often difficult because of the lack of visibility into the signal coverage. Good WLAN monitoring products can significantly reduce the operating costs while ensuring 24x7 network reliability and performance. The cost estimate appears below:

\begin{tabular}{c|l|c|c|c} 
Item & Activities & Unit Price & Qty & Total \\
\hline 1 & Access Controller & $\$ 699.00$ & 2 & $\$ 1,398.00$ \\
\hline 2 & Unidirectional antennas & $\$ 199.00$ & 2 & $\$ 398.00$ \\
\hline 3 & Ethernet switch $(\mathrm{PoE})$ & $\$ 895.00$ & 1 & $\$ 895.00$ \\
\hline 4 & Access Points & $\$ 599.00$ & 3 & $\$ 1,797.00$ \\
\hline 5 & Miscellaneous: Cables, connectors, external enclosures, etc. & $\$ 500.00$ & 1 & $\$ 500.00$ \\
\hline 6 & Network Management System for 50 APs & $\$ 1,199.00$ & 1 & $\$ 1,199.00$ \\
\hline 7 & installation, provisioning and commissioning (price per hour) & $\$ 250.00$ & \multirow{2}{*}{10} & $\$ 2,500.00$ \\
\hline & & & Total & $\$ 8,687.00$ \\
\hline
\end{tabular}

Issues in Information Systems 